\title{
Defining the Main Parameters of Hydro-Dumping at Open Pits
}

\author{
Jacek Engel ${ }^{1}$, Josef Mihok $^{1}$, Radim Rybar ${ }^{1}$, and Maxim Tyulenev ${ }^{2, *}$ \\ ${ }^{1}$ Technical University of Kosice, Faculty of Mining, Ecology, Process Control and Geotechnologies, \\ Letná 9, 04200 Kosice, Slovak republic \\ ${ }^{2}$ T.F. Gorbachev Kuzbass State Technical University, Surveying and Geology Department, 650000 \\ Kemerovo, 28 Vesennya st., Russian Federation
}

\begin{abstract}
Currently, the mining industry faces the problem of intensifying extraction and processing of mineral raw materials with minimal costs for the development of mineral deposits. It should be noted that the greatest degree of technological processes mechanization in the development of deposits is achieved by means of hydromechanization. For example, in the development of placer deposits by the open pit method, the application of hydromechanization, with the appropriate parameters, ensures the necessary disintegration of clay inclusions at minimal cost. It allows solving the issues of the most complete extraction of a useful component. Increasing the effectiveness of the use of a hydromechanized method is favored by the use of bulldozers, excavators and other open pit mining machinery for loosening the rocks. With a rational design of the circulating water supply systems, hydromechanization means using the methods of limited water consumption. The hydraulic method for mining mineral deposits is taken to the leading place from the point of view of environmental protection. At the same time, the greatest environmental effect is achieved under the condition of an accurate calculation of the main parameters of hydro-dumps.
\end{abstract}

\section{Introduction}

Hydromining development is the destruction and washout of rocks by the water flow emitted from the hydro-monitor under high pressure. The rock destruction occurs due to the energy of the jet blow, the filtration of water through the pores of the rock, the weakening of the adhesion between its particles, moistening and soaking it, dissolution of salts contained in the rock [1-2].

The technology of hydromining presents cutting the face with a stream and washing away the rock crashed by and filled with the water into the sump of the dredge pump or to the gravity pulp drainage trench [3-5].

In the development of loose, cohesionless or pre-loosened rocks, the hydromining process consists of one operation. In this case, there is no need in cutting the bench. The loose rock is simultaneously saturated and washed off with water.

\footnotetext{
* Corresponding author: tma.geolog@,kuzstu.ru
} 
In the development of cohesive rocks, which include loams and clays of varying density, as well as consolidated sand and gravel, the development process consists of two operations: cutting and washing out [6-7].

The most time-consuming work in hydro-monitor development is cutting the bench. During this period, the saturation of the water flow by the rock is extremely low. In heavy loamy and especially clay soils $60-70 \%$ of the working time is spent on cutting. With less dense rocks, the time for cutting is $30-50 \%$. The scheme for stope and subsequent underreaming is chosen depending on the type of rocks composing the bench and their physical-and-mechanical properties [8].

\section{Materials and Methods}

The calculation of the hydro-dump includes the following basic parameters: the actual volume of the rock after its placement in the dump; height, width and length of the dump; slopes of the surface of the washed up dump. Calculation of the settling pond includes the definition of such parameters as: the minimum necessary length of the settling pond; efficiency of clarification of recycled water; thickness and length of clay deposits; water balance; parameters of the dam and spillway devices. The capacity of the dump depends on the volume of the stacked rock, its granulometric composition, the rate of fluid loss and compaction.

The capacity of the hydro-dump depends on the volume of the stacked rock, its granulometric composition, the rate of filtration-loss quality and thickening. Gravel-sandy and sandy-loamy rocks give up water quickly (they are precipitated in water), slightly changing their volume on the dump compared to the original in the pillar. Clay rocks have low water filtration-loss and significantly increase their volume in the dump as compared to the volume in the pillar. The volume of the dump is also defined by the condition of providing clarification of the return water.

It should be noted that round stones do not enter the dump, but are stored directly in the face, and clay particles precipitate in the settling pond. Therefore, the volume of the hydrodump is determined without taking them into account.

\section{Results and Discussion}

The volume of accumulated rocks in the hydro-dump at the end of its operation $V_{\text {subsoil }}$ end $\left(\mathrm{m}^{3}\right)$ :

$$
V_{\text {subsoil }}^{\text {end }}=K_{s} \times V_{\text {subsoil }}
$$

$K_{s}$ - the loosening coefficient of subsoil (tails) in a hydro-dump; $V_{\text {subsoil }}$ - the volume of washed subsoil (tails) entering the hydraulic dump in a dense mass for the entire period of its operation, $\mathrm{m}^{3}$ :

$$
V_{\text {subsoil }}=L_{q} \times B_{q} \times H_{\text {over }}\left(1-\frac{K_{g}}{100}-\frac{K_{c l}}{100}\right) / k_{d}
$$

$L_{q}$ and $B_{q}$ are the length and width of the pit contour, $\mathrm{m} ; H_{\text {over }}-$ the thickness of overburden rocks, m; $k_{d}$ - the loosening coefficient of rocks in the massif; $K_{g}$ and $K_{c l}$ - the content of gravel and clay particles in the subsoil, $\%$.

Figure 1 shows the possible forms of capacity for the organization of the hydro-dump, depending on the terrain or the presence of mined-out space. The chosen form is associated with its variant and the place for pulp discharge is defined. Table 1 gives the approximate values of the average slopes of the washed surface of the hydro-dump. 

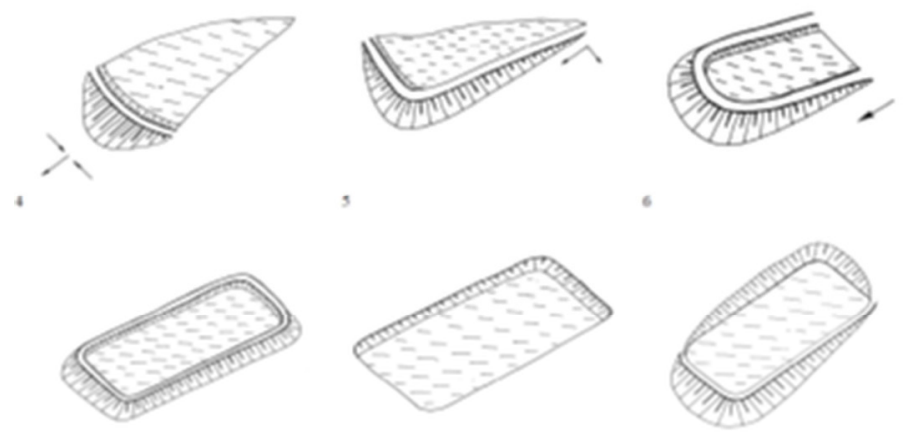

Fig. 1. Options for settling ponds on the ground: 1) in the valley (three-slope); 2) on a two-slope slope; 3 ) on a slope; 4) on a flat surface; 5) in the worked out space; 6) combined.

Table 1. The values of loosening coefficient of the hydro-dump and the slopes of washed surface for different rocks.

\begin{tabular}{|l|c|c|c|}
\hline \multicolumn{1}{|c|}{ Kind of subsoils } & $\begin{array}{c}\text { Loosening } \\
\text { coefficient }\left(\boldsymbol{K}_{\boldsymbol{s}}\right)\end{array}$ & \multicolumn{2}{c|}{ The incline of hydro-dump surface } \\
\cline { 3 - 4 } & & above-water part & underwater part \\
\hline $\begin{array}{l}\text { Heavy tenacious clay (more } \\
\text { than 50\%) }\end{array}$ & $1.5-2.0$ & $0.015-0.007$ & Less than 0.015 \\
\hline Plain ball clay (40\%) & $1.5-1.7$ & $0.015-0.007$ & $0.02-0.01$ \\
\hline Clay with sand & $1.4-1.5$ & $0.02-0.008$ & $0.03-0.02$ \\
\hline Heavy clay loam & $1.45-1.5$ & $0.02-0.008$ & $0.03-0.02$ \\
\hline Medium-textured loam & $1.2-1.45$ & $0.025-0.01$ & $0.04-0.02$ \\
\hline Light loam & $1.2-1.3$ & $0.025-0.01$ & $0.05-0.03$ \\
\hline Medium sandy loam & $1.15-1.2$ & $0.03-0.01$ & $0.06-0.03$ \\
\hline Loamy light sand & $1.05-1.15$ & $0.03-0.01$ & $0.07-0.04$ \\
\hline Short-grained sand & $1.1-1.15$ & $0.04-0.03$ & $0.15-0.10$ \\
\hline Medium-grained sand & $1.05-1.1$ & $0.07-0.06$ & $0.20-0.15$ \\
\hline Hard-grained sand & $1.0-1.05$ & $0.20-0.10$ & $0.30-0.20$ \\
\hline Gravel & $1.05-1.1$ & $0.70-0.50$ & $1.00-0.70$ \\
\hline
\end{tabular}

Depending on the hydro-dump height $H_{h d}$, the area of hydro-dump on longitudinal section $S_{h d}\left(\mathrm{~m}^{2}\right)$ :

$$
S_{h d}=0.5 H_{h d} \times L_{h d}
$$

$L_{h d}-$ conventional length of hydro-dump, $\mathrm{m}$ :

$$
L_{h d}=H_{h d}\left[1 /\left(0.5\left(I_{o}+I_{u}\right) \pm i\right)\right]
$$

$I o$ and $I u$ - the incline of the surface of in-washed tails for in-wash of above-water and underwater parts pf the hydro-dump (Tab. 1); $i$ - the longitude incline of the landscape in the place of hydro-dump location.

When hydro-dump is in-washed from the side of the dam, the incline has positive sign $(+)$, for in-washing towards the dam - the negative sign $(-)$, Figure 2.

Minimum width of the hydro-dump $B_{w}{ }^{\min }(\mathrm{m})$ :

$$
B_{w}^{\text {min }}=V_{\text {subsoil }}^{\text {end }} / S_{\text {hd }}
$$


After making a decision on the location of the hydro-dump (according to safety, environmental and economic reasons) - right or left side relative to the quarry, in the valley higher or lower along the slope relative to the quarry - the estimated width of the hydrodump is defined. The width of the hydro-dump can be increased or decreased by changing the adopted height of the hydro-dump and recalculating $L_{h d}, S_{h d}$, and $B_{w}{ }^{\min }$.

For further calculations, the actual height of the hydro-dump is indicated as $h_{h d}$.

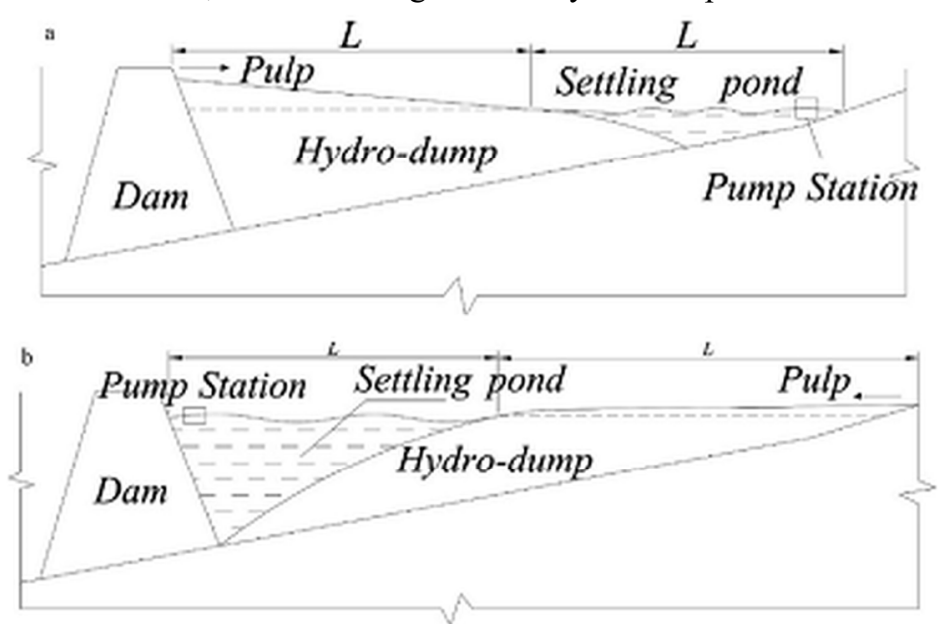

Fig. 2. The schemes of washing directions for a hydro-dump.

Settling pond.

Basic design parameters of the settling pond: length, width and thickness of clay particles in the settling pond; length, width and depth of water in the pond; minimum settling pond length; content of ground fractions in process water (Figure 3).

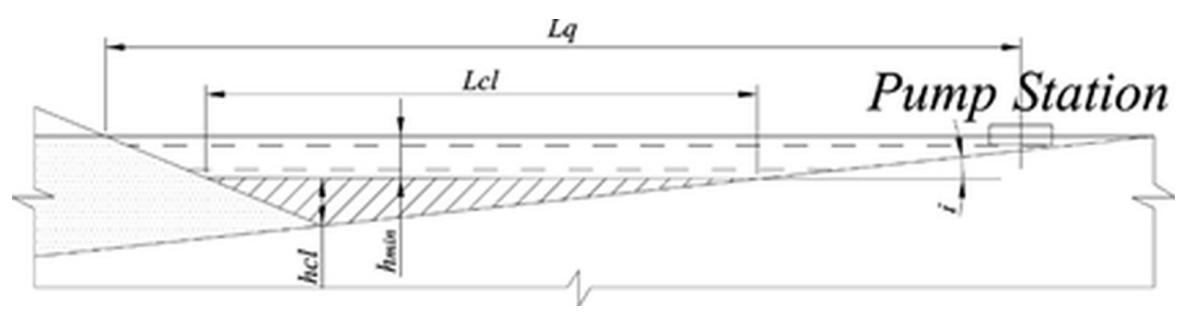

Fig. 3. Basic design parameters of the settling pond.

The volume of the dump of finely dispersed rocks (clay particles) in the settling pond at the end of its operation $V_{s p}$ end $\left(\mathrm{m}^{3}\right)$ :

$$
V_{s p}^{\text {end }}=L_{q} \times B_{q} \times H_{\text {over }}\left(K_{c l} / 100\right) / k_{d}
$$

The area of the clay particles dump along the longitudinal section $\left(\mathrm{m}^{2}\right)$ :

$$
S_{s p}=V_{s p}^{e n d} / \mathrm{B}_{q}
$$

or:

$$
S_{s p}=0.5 h_{c l} \times L_{c l}
$$

$h_{c l}$ and $L_{c l}$ are the height and length of the clay particles dump in the settling pond, respectively, $\mathrm{m}$ :

$$
L_{c l}=h_{c l} \times\left(1 / I_{u}+1 / i\right)
$$


The minimum length of the settling pond at the end of its operation $(\mathrm{m})$ :

$$
L_{c l}=\frac{h_{\text {min }}+H_{\text {drain }}}{i}
$$

$h_{\min }$ - the minimum depth of the settling pond at the end of its operation, $\mathrm{m} ; \mathrm{h}_{\min }=(10-$ $15) H_{c} ; H_{\text {drain }}$ - the height of draining layer at the overflow edge $\left(H_{\text {drain }}=0.1-0.15 \mathrm{~m}\right)$.

The limiting rate of ground particles sedimentation in the settling pond $\omega_{\text {sed }}$ (at the settling rate more than maximum permissible - ground particles are completely stored in the settling pond, at the settling rate less than maximum permissible - the ground particles enter the drain trunk or water intake of the pumping station):

$$
\omega_{\text {sed }}=\lambda_{s} \times v_{s p} \times h_{\text {min }} / L_{c l}
$$

$\lambda_{s}$ - the assurance coefficient that takes into account the imperfection of the process of particle deposition due to the absence of complete rest and the presence of constrained conditions $\lambda_{s}=1.5-3.6$, greater value is taken in the presence of a large number of finely dispersed ground particles; $v_{s p}$ - the speed of water flow in the settling pond, $\mathrm{m} / \mathrm{sec}$ :

$$
v_{s p}=Q_{w . h d} / S_{w \cdot f d}
$$

$Q_{w . h d}$ - the volume of water, inflowing to the surface of hydro-dump in-wash, $\mathrm{m}^{3} / \mathrm{sec}$;

$S_{w . h d}$ - the area of wetted cross-section of water in the settling pond, $\mathrm{m}^{2}$ :

$$
S_{w . h d}=B_{w}^{\min } \times h_{\text {min }} .
$$

Calculation of the dam.

The volume of rock placed in the dam body of the hydro-dump and the settling pond $V_{\text {dam }}$ $\left(\mathrm{m}^{3}\right)$ :

$$
V_{\text {dam }}=S_{\text {dam }} \times L_{\text {dam }}
$$

$L_{d a m}$ - the length of the dam at the level of $0.5 h_{d a m}, \mathrm{~m}$ ( $h_{\text {dam }}$ is the final height of the dam).

The location of hydro-dump is determined according to the plan taking into account its shape. For example, the plan assumes the $L$-shaped form of the dam, then the calculated values are $L_{d a m}=500 \mathrm{~m}$ and $B_{d a m}=400 \mathrm{~m}$. The maximum length of the dam in the plan is $L_{\text {dam.max }}=500+400=900 \mathrm{~m} ; S_{\text {dam }}$ is the cross-sectional area of the dam, $\mathrm{m}^{2}$ :

$$
S_{\text {dam }}=0.5\left(B_{c r}+B_{\text {base }}\right) \times h_{c r}
$$

$B_{c r}$ - the width of the crest of a dam (Table 2), m; $B_{\text {base }}$ - the width of the dam on the base, $\mathrm{m} ; h_{c r}$ is the minimum elevation of the crest of a dam above the water level, $\mathrm{m}\left(h_{c r}=0.8-\right.$ $1,3 \mathrm{~m})$ :

$$
h_{c r}=C+Z
$$

$C$ - the height of the wind wave, $\mathrm{m} ; Z$ - the height margin $(\mathrm{Z}=0.5-0.75 \mathrm{~m})$.

$$
C=0.075 V_{\text {wind }}
$$

$V_{\text {wind }}$ - the maximum wind speed for 10 years, $\mathrm{m} / \mathrm{sec}$.

Table 2. The width of the top for the earth dams with the road on top.

\begin{tabular}{|l|c|c|c|c|c|}
\hline \multirow{2}{*}{ Road elements } & \multicolumn{3}{|l|}{ Road class } \\
\cline { 2 - 6 } & I & II & III & IV & V \\
\hline Number of traffic paths & 4 & 2 & 2 & $1-2$ & $1-2$ \\
\hline Traffic path width, m & 3.5 & 3.5 & 3.5 & 3.0 & 3.0 \\
\hline
\end{tabular}




\begin{tabular}{|l|l|l|l|l|l|}
\hline The width of the top for the dams, $\mathrm{m}$ & 23 & 12 & 12 & 10 & 10 \\
\hline
\end{tabular}

The width of the top for the dams without the road in top must be at least $3 \mathrm{~m}$.

The calculated height of the dam is increased by the shrinkage coefficient $\left(C_{s h r}\right)$, equal to $1.15-1.20 ; 1.10-1.15$ and $1.05-1.10$, respectively, for clay rocks and loam, sandy loam and sand, gravel-sand mixtures.

The width of the dam on the base is determined graphically or analytically. In addition to the height of the dam, it is necessary to know the width of its top and the horizontal equivalents.

\section{Conclusion}

In the process of technological assessment of the use of hydromechanization means, special attention should be paid to the high degree of ecological safety of this method. Reliable organization of recycling water supply systems ensures its high rating relative to other methods, even in seasonal mining operations. It should be noted that the use of hydromechanization means can be provided not only as a whole in the development of the deposit, but also separately in any technological process when conducting open mining operations.

\section{References}

1. N. Demirel, S. Frimpong, Reclamation and Environment, 23:1, 4-20 (2009)

2. K. Hino, Quarterly of the Colorado School of Mines, 51(3) (1956)

3. V. Golik, Yu. Dmitrak, E3S Web Conf., 21, 01018 (2017)

4. V. Golik, Yu. Dmitrak, E3S Web Conf., 21, 01025 (2017)

5. J. Rowers, H. Krier, UILD ENG, 84, 4014 (1984)

6. G. Duvall, Propagation of Plane Shock Wales in a Stress-Relaxing Medium in Stress waves in Anelastie Solids, (Springer Verlag, Berlin, 1964)

7. A. V. Selyukov, Journal of Mining Science, 51:5, 879-887 (2015)

8. A. V. Selyukov, Bulletin of the Tomsk Polytechnic University, Geo Assets Engineering, 326:12, 60-71 (2015) 